\title{
A Discussion on How to Apply Smart Data for Precision Marketing in the Global Economy: Asian Context
}

\section{Sandy Zhu}

The Business School, Bournemouth University, UK

Email: sandyzhu010690@gmail.com

\section{Abstract:}

The aim of the research is to provide support for the application of smart data, precision marketing, and business analysis and in so doing, it is aimed to contribute to the further sustainable development of the economy. At present, intelligent technologies such as artificial intelligence and big data are developing in full swing, and various application scenarios are gradually being launched. Smart data is a new sort of database in combination with artificial intelligence and big data technology, which makes artificial intelligence technology and big data the core concepts and the foundation of digital smart data. With smart data, companies could apply precision marketing to better reach their target consumers, push notifications at the right time, advertise the products and services consumers are interested in, and establish personalised marketing communication with each consumer in order to increase marketing efficiency. Undoubtedly, precision marketing has become the top priority in the development of the digital marketing industry, and it is becoming increasingly popular. The paper is based on this perspective and starts with an overview of smart data. The definition and development status of smart data are first reviewed, followed by an analysis of the application of smart data technology and precision marketing in digital marketing.

Keywords:

smart data; precision marketing; customer persona

\section{Introduction}

\subsection{Background of the Study}

With the rapid development of new technology, we produce massive data in our daily routine, and the volume of data generated every day in the world will reach 491 Exabytes in 2025 (Patrizio, 2018). Data has become increasingly integrated and immersive, profoundly affecting our lives. Current data technology is being widely used in all walks of life, and it has also been fully applied in the marketing industry, especially in precision marketing. As we enter the $5 \mathrm{G}$ era, almost everything has become connected, and the distance between time and space is significantly compressed. Meantime, we are advancing in globalisation, step by step. The development of smart data has greatly improved the operational efficiency of each industry and the sub-fields. Embracing the growth and development of smart data is crucial to future marketing initiatives. Especially in recent years, smart data has been used in customer service, marketing, and other fields (Qu, 2020). The gradual deepening of research and application has brought opportunities and challenges for this industry and the market. Every day, companies are using artificial smart data platforms to optimise their processes, reduce overheads, shorten turnaround times, and increase efficiency. In an era of such rapid technological development, the pace of social operations, the ability of humans to process information, and the impact of technology on social progress are all accelerating, and the rate of increase is unprecedented (Murgai, 2018). This availability of data showcases that smart data can be useful in the optimal usage of resources while making informed decisions (Alam et 


\section{Economit Journal: Scientific Journal of Accountancy, Management and Finance ISSN: 2775-5827 (Online), 2775-5819 (Print)}

Vol. 1, No. 2, May 2021, Page: 70-84

Email: economitjournal@gmail.com

al., 2014). By strengthening the understanding of precision marketing, combining the characteristics of smart data technology, and producing the best possible results based on the advantages, the application of precision marketing will become more innovative and smarter. The article introduces smart data and precision marketing and analyses the application of smart data technology and precision marketing in the Asian context. Embracing the growth and development of smart data is crucial to future marketing initiatives. Especially in recent years, smart data has been used in customer service, marketing, and other fields (Qu, 2020). The gradual deepening of research and application has brought opportunities and challenges for this industry and the market. Every day, companies are using artificial smart data platforms to optimise their processes, reduce overheads, shorten turnaround times, and increase efficiency. In an era of such rapid technological development, the pace of social operations, the ability of humans to process information, and the impact of technology on social progress are all accelerating, and the rate of increase is unprecedented (Murgai, 2018). This availability of data showcases that smart data can be useful in the optimal usage of resources while making informed decisions (Alam et al., 2014). By strengthening the understanding of precision marketing, combining the characteristics of smart data technology, and producing the best possible results based on the advantages, the application of precision marketing will become more innovative and smarter. The article introduces smart data and precision marketing and analyses the application of smart data technology and precision marketing in the Asian context.

\subsection{Rationale for the Study}

As the research on smart data and precision marketing is relatively limited, the application of smart data in the current environment is in the exploratory stage. Existing research on precision marketing basically focuses on accurate advertising and algorithmrelated content. The article combines predecessors' research results with personal evaluations, based on the theoretical discussion, with case analysis of smart data and precision marketing plans in the Asian context, and presents the author's recommendations for resolution of existing problems.

\section{Review of Literatures}

\subsection{Smart Data}

\section{a. The Concept of Smart Data}

Smart data is an information asset. This information asset has stronger analytical, pertinence, and optimisation capabilities through a new processing model. It cannot be collected, processed, and managed through conventional applications. It is a diversified asset that is constantly updated and changed. According to Mayer-Schoenberger and Cukier (2013), smart data uses all data for analysis and processing, rather than traditional stochastic calculus or sample surveys.

According to the forecast of the market research organisation IDC, the annual growth rate of the data volume on a global scale in the future will be maintained at about $40.3 \%$ (Patrizio, 2018). It can be said that every behaviour will generate certain data, such as health care, online chat, e-commerce, search history, etc. In order to maintain their competitive advantage in the same industry, companies strive to adapt to the market environment, formulate dynamic strategic layouts, and improve the efficiency of data applications, thereby promoting the improvement of product content, services, and framework transformation. However, according to a survey (Suh, 2015), companies are currently blind to smart data research and investment, which is reflected in the fact that companies often value the amount 
of information in data, while ignoring the value and effectiveness of the information. In fact, the quality of data is not determined by its size. The larger the volume of the data, the more useless information we have. How should we process the massive data we have? Fundamentally, big data includes dynamic and real-time data, first-party data (accumulated by enterprise applications), second-party data, and third-party data. It is necessary to recognise valuable data and process such data by specialised algorithms with the proper business processes to achieve business automation. These extracted and processed data are smart data.

Smart data can be seen as a subset of big data, which can be used to solve problems. Specifically, activating, analysing, and summarising unstructured data and structured data helps executive teams to make scientific decisions, improve the company's competitive advantage in the same industry, and thereby increase the overall revenue of the company. A machine learning research (Hamid et al., 2017) indicates: artificial intelligence and machine learning are developing in the direction of "human-machine coexistence"; that is, intelligent machines obtain certain insights through work and integrate them with human thinking, combining ideas to improve people's ability to judge and make decisions about things. This is an efficient professional interaction, which prompts both parties to do what they do best.

The generation of smart data helps companies better understand customer interests and behaviours, improves corporate marketing efficiency and consumer engagement rate, and promotes the sustainable development of companies. As the economy develops and science and technology improve, data technology is widely used in the business field, in marketing, advertising, corporate data needs, business insights, etc. At this stage, smart data technology covers a wide range of industries, including life sciences, online advertising, energy, Internet of Things, finance, sales and marketing, customer experience, network security, etc., as shown in Figure 1. Furthermore, the scope of digital marketing is gradually increasing. Since the mid to late 1990s, marketing has gone through four stages: 1. Simple manual workshop stage; 2. Traditional advertising stage; 3. Repetitive massive promote stage; 4. Modern marketing automation stage. Brands are currently in the era of digital marketing, and marketers' demand for data is gradually increasing. If companies want to achieve digital precision marketing, they must have scientific and professional technology and data-driven marketing methods.

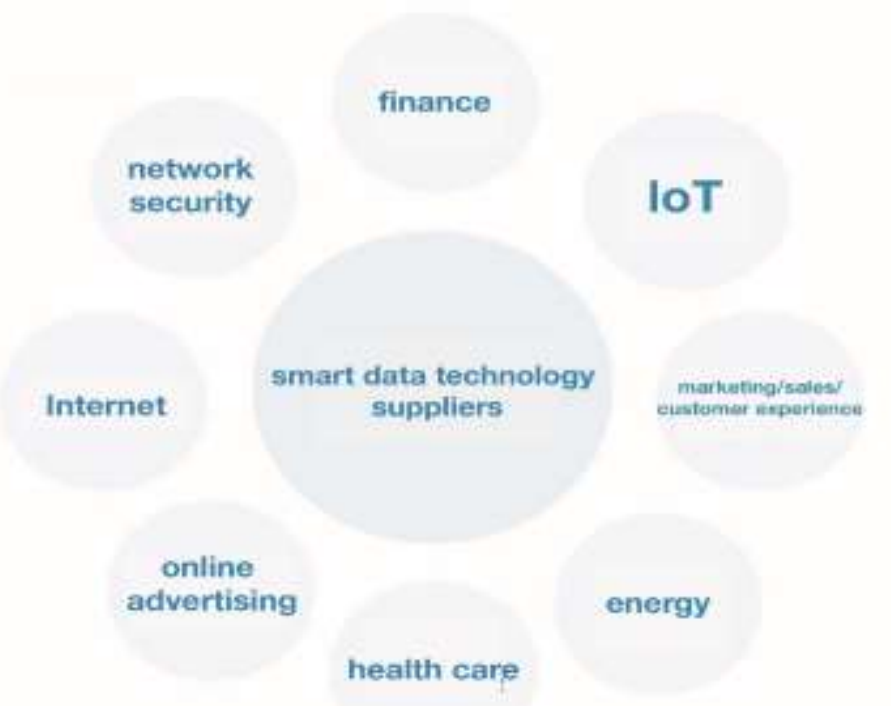

Figure 1. Industries Using Smart Data Technology (Adapted from Socialbeta, 2017) 


\section{b. The Features of Smart Data}

Koeck (as cited in Salazar, 2016) claimed that big data has many advantages; however, it is not a valuable data stream. Smart data can discover the master data using the fastest method, distinguishing important information in the shortest time, which will improve internal work efficiency and optimise accuracy of decision making.

IBM proposes that smart data has five V characteristics: Value (low value density), Velocity (high speed), Variety (diversity), Volume (large amount), and Veracity (authenticity) (Marr, 2015). Smart data technology helps to process high volume data, including historical data and real-time updated data, and summarise a certain model or pattern or predict future trends or possibilities. As described in the following chart (Figure 2):

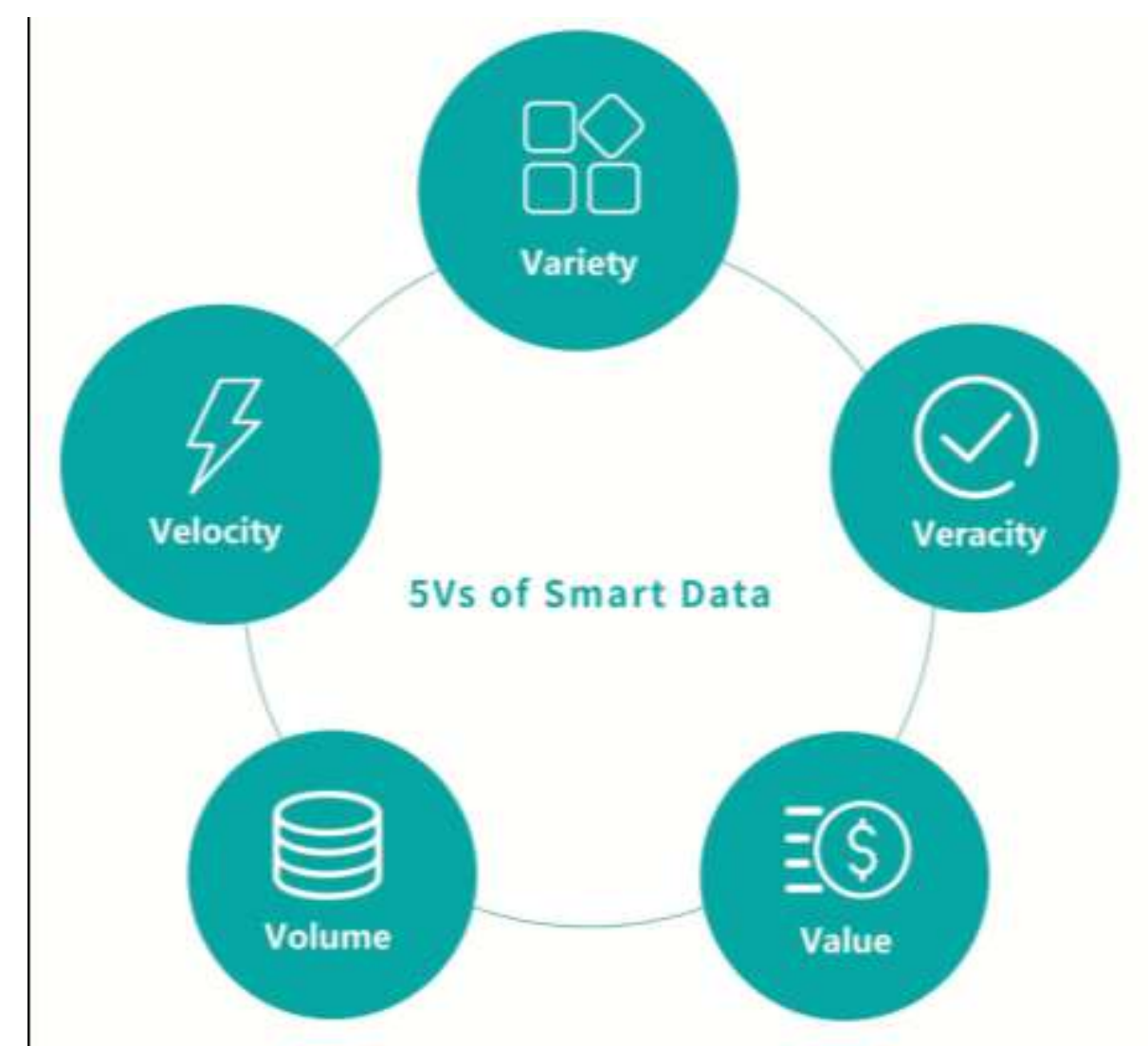

Figure 2. 5Vs of Smart Data (Adapted from SocialBeta, 2017)

Volume, Velocity, and Variety are related to the data generation and the method of collection and storage of data, while the two aspects of Veracity and Value are related to the quality and availability of data (Erevelles et al., 2016). Thus, it is not difficult to discover that, compared with big data's "noise", the four core features of smart data are: Practical, operable, and cross-platform, and multi-channel collectible. Businesses, especially large-sized companies, normally have detailed multi-platforms and a large number of brands, and therefore have requirements of cross-channel marketing communication (Neslin \& Shankar 2009). The smart database can be roughly divided into real-time data and dynamic data (Liu et al., 2020), it can be integrated into a closed-loop data collector based on algorithms and machine learning technology. 


\subsection{Precision Marketing}

\section{a. The Concept of Precision Marketing}

The definition of precision marketing was first proposed by Kotler and Armstrong (2005). He believed that precision marketing is a result-oriented marketing strategy; it is necessary for enterprises to apply it to enhance communication and sales efficiency and to have a high return with a limited budget.

In 2004, Jeff Zabin and Gresh Brebach introduced their own concept: precision marketing refers to taking the buyer's market as the core, adopting targeted marketing methods at each stage of the consumer's life cycle, and meeting consumer needs through the "3 right", which are: the right time, the right channel, and the right price to improve the competitive advantage of the company and marketing precision, and promote sustainable development of the company.

The new type of precision marketing uses modern technology to establish a consumer database and persona. By understanding consumers' personal preferences and behaviours and choosing appropriate communication channels, consumers will have a strong interest and purchasing intention when making buying decisions. Meanwhile, Zabin and Brebach (2004) also suggested specific steps according to the concept of three-stage precision marketing (based on the consumer life cycle): (1) Attracting: This is the main purpose, to attract customers through various marketing methods and establish a safe and stable relationship; (2) Retaining: at this stage, companies need to sustain interaction with customers, deepen customer relationships, and increase customers' trust and love for the company; (3) Leveraging: it is mainly profit-oriented, to further expand the degree of closeness, and to discover new consumer behaviour, needs, and purchasing models.

\section{b. The Features of Precision Marketing}

A comprehensive analysis of the current definition of precision marketing (Qin and Zhao, 2016) reveals that precision marketing essentially takes consumers as the core target, looking for correct channels, times, places, prices, products, and personalised correspondence with customers. Meanwhile, it can be summarised that the crucial point of precision marketing is "correctness and accuracy", which means, each link of the process must be precise. Enterprises desire to collect precise and predictable data so that they can optimise the performance of the target market. According to Zhao and Ma (2017), the theoretical basis of precision marketing is: 4C theory, transaction cost theory, and communication theory. Therefore, from the correct matching of prices and channels, to increase sales to meet KPIs, the features of precision marketing are mainly reflected accordingly in the following four aspects:

(1) Consumer targeting. Target customers are a crucial part of precision marketing. It is the foundation of other marketing methods and strategies. Consumer targeting refers to the precise division of customers and the adoption of appropriate marketing communications for target customers to achieve high efficiency of marketing. Nowadays, precision marketing technology can be applied to research and data in high-tech and massive databases analysed to discover the target customers, and provide relevant products or services to them via the right channel.

(2) High cost-effectiveness. Precision marketing aims at low cost and high revenue. This requires companies to adopt various methods to reduce costs after discovering target customers, so as to maximise revenue. Therefore, companies generally adopt lowercost marketing methods for precision marketing, such as online advertising and social media marketing. 
(3) Measurable effects. The development of high-end technology makes it more convenient and comprehensive to monitor the process and results of precision marketing. Technical support helps the marketing process and effects delivery to markets more accurately, thereby optimising the marketing strategies. At the same time, marketers can analyse accurately the factors that affect the marketing effect, so as to make appropriate adjustments to marketing strategies and planning in order to achieve the marketing goals.

(4) Personalised communication. Traditional marketing usually refers to direct communication between the company and the mass customer, in which the message is the same. This communication method will be restricted by time, place, form, and other aspects (Yu et al., 2020). Consumers' understanding of the company is often affected by various factors which affect the decision making of customers. Specifically, the limitation of the information and monotonous communication methods make customers lack a detailed understanding of the products or services. Personalised communication is to make brands become both the message sender and the receiver; after receiving feedback from consumers, companies should interact with consumers in their preferred way and tone. The efficiency of communication will be significantly improved. Enterprises could provide customers a platform for communication, such as establish a discussion area, and invite key opinion leaders to advertise their product, thus influencing purchasing behaviour by word of mouth. Compared with traditional marketing, this is a fundamental feature of precision marketing.

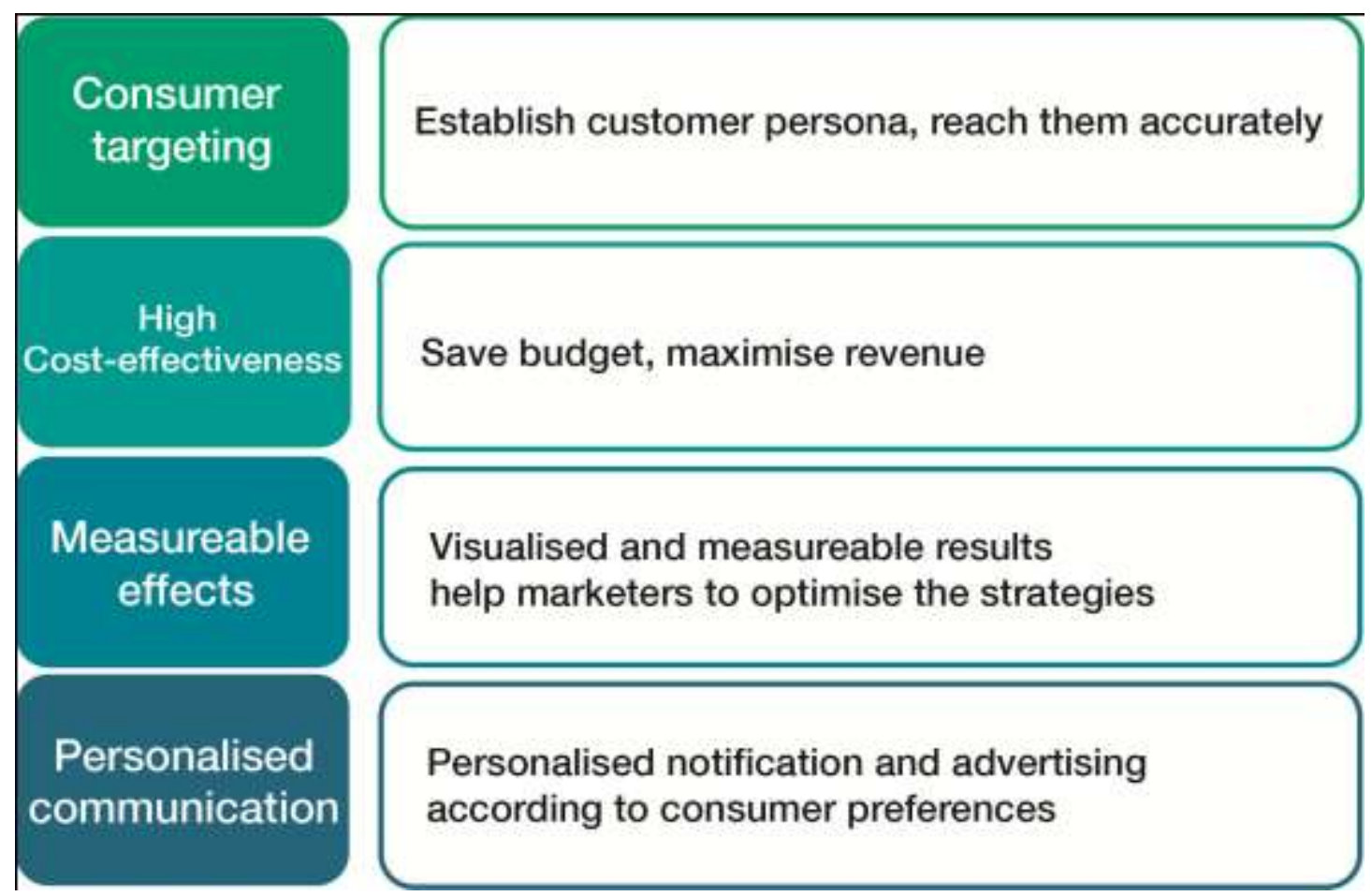

Figure 3. Four Features of Precision Marketing (Adapted from Qqcjw, 2018)

\subsection{Approach to Application of Smart Data and Precision Marketing in the Asian} Market

a. Shiseido

Shiseido is the leading Japanese brand in the cosmetic industry. Since 1937, for the first time, Shiseido has made marketing strategies aimed at customer loyalty. In 2012, the arrival of the new era of big data provided a perfect opportunity for Shiseido to implement 
these strategies. Therefore, Shiseido launched the Watashi plus system in order to provide customers a high-quality experience, establish a better brand image, and discover the potential value of the brand. This platform has brought Shiseido's marketing into a new stage, broadening their marketing channels both virtually and realistically. In other words, Watashi plus could assist Shiseido to have customised interactive communications with consumers, so that customers understand the detailed information of the product in their preferred method and perspective. Meanwhile, Shiseido will receive customers' feedback from the platform by analysing smart data, and improve their marketing communication and strategies; this also makes the system smarter through constantly learning and analysing (Treasure Data, 2020).

However, consumer preferences change in real-time with various factors such as environment and moods, which means marketing strategies should also be updated continuously and automatically. Chief analyst of Shiseido's marketing department, Kenji Yoshimoto (as cited in Treasure Data, 2020), has pointed out that cons umer preferences are swingable. It is significant to fully integrate historical data with real-time data to predict a possible tenor for push notifications that leads to customer delight, and to develop relevant marketing strategies.

Shiseido has carried out research and estimation after detailed analysis of dozens of consumers. They discovered that the consumer data was isolated in their internal database, and the dynamic data resource cannot be found in their existing database. The only method is to continue collecting dynamic data and combine both dynamic and non-dynamic data to complete customer personas and identification.

Therefore, Shiseido got involved in the CDP (Customer Data Platform, provided by Treasure Data) platform and set up an interface with Watashi plus to add PoS, IoT, website, SaaS, consumer population, behavioural data, and offline data, etc. Finally, Shiseido visualised consumers and sales data and simplified processing flow, basically it contains four steps: collect and integrate all raw data, process mass data to unified data file, analyse data to segment consumers and provide prediction of proper marketing strategies and content accordingly, finally advertise to consumers through multiple platform with customised information, for example social media, email etc., as shown in Figure 4.

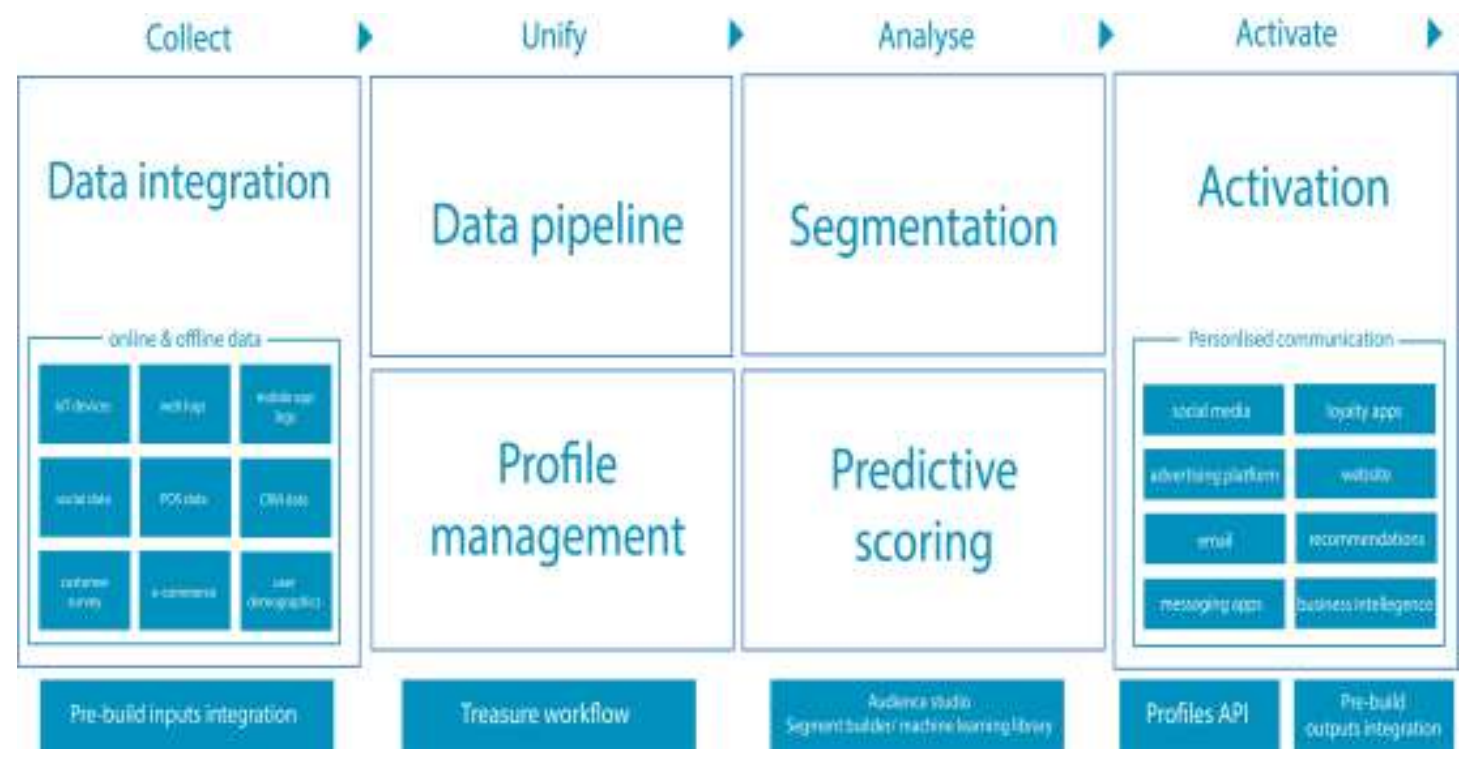

Figure 4. Advanced Customer Data Platform (Adapted from Treasure Data, 2020) 
Due to the features of smart data and precision marketing, it is more convenient to discover and obtain hidden and important information by collecting and analysing customer data. Therefore, with the popularity and maturity of smart data technologies and precision marketing, it can be speculated that the long-standing problems, for instance "What is the customer's name, are customers satisfied with our products, which shopping platforms are customers most likely to use, and why customers are interested in our products", can be ameliorated.

\subsection{Trip (Known as Ctrip before 2020)}

Trip is the top Chinese booking website brand in the travel industry (Trip, 2020). It has an extremely detailed database, including personalised notification and content display for each consumer; it also has a strong capability to predict consumer behaviour and preferences, all of which are widely used in smart data and precision marketing strategies. In addition, Trip has a noteworthy track record in other fields, for instance room scheduling, ticket sorting, business trip reimbursement claims, etc., and has achieved terrific outcomes. In 2019, Trip's gross merchandise volume reached CNY 865 billion, and it has a year-on-year increase of $19 \%$. The company's annual gross margin increased by $94 \%$ year-on-year to CNY 5 billion, which was higher than the total revenue of the past five years (Eastmoney, 2020). Most importantly, Trip can also analyse consumer preferences according to their orders, browsing histories and behaviours, choices, etc., and then conduct effective marketing communication, which greatly improves consumers' purchasing experience, and optimises the accuracy of precision marketing (Shujike, 2019).

The intelligent data platform of Trip is basically composed of several aspects, which are registration, collection, calculation, storage/query, and monitoring (Shujike, 2019). As demonstrated in the structural drawing below (Figure 5), all consumer data will be registered through the "user profile" platform. After verification, the data will be transferred to the "data warehouse". Thus, the purchasing history, consumer information, and order queries are random, massive, and accurate.

When collecting all the data needed, the next step is to classify different labels for each consumer and make customer persona. After the consumer's information is processed through specialised AI algorithms and models which could analyse real-time and non-real-time (streaming) dynamic data, it will be sent to the "persona database".

Faced with various occasions and scenarios, the system will provide real-time and batch query APIs for each caller to use. The real-time channel focuses on availability, and the batch channel focuses on throughput. Finally, all customer personas are effectively evaluated and controlled in the monitoring platform to ensure the accuracy of the consumer data. 


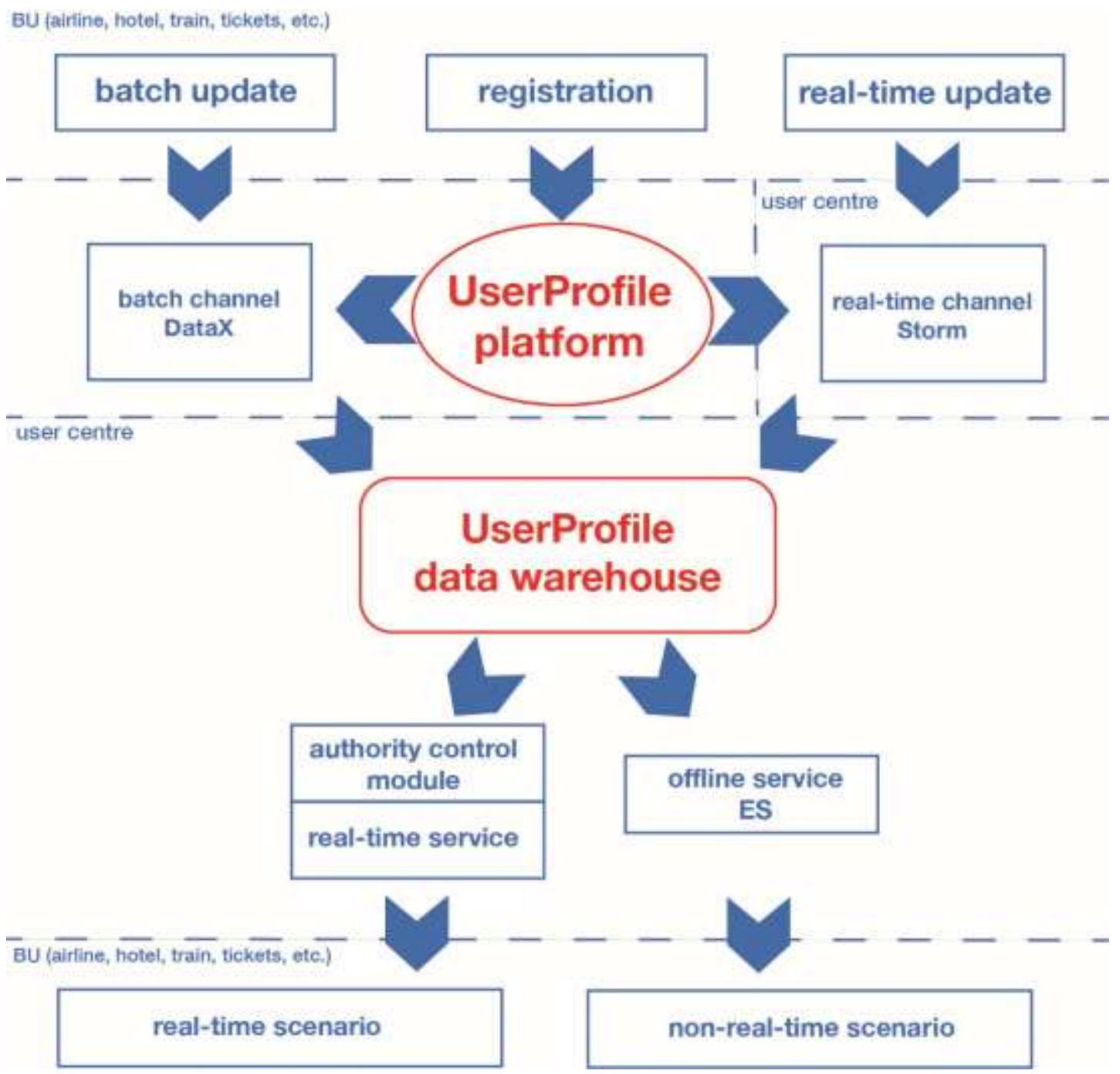

Figure 5. Flow Chart of UserProfile System (Adapted from Shujike, 2019)

According to Zhou (Shujike, 2019), the crucial points of this framework are as follows:

(1) There are asynchronous and real-time channels, to meet the needs of different scenarios and various consumer personas. Factual data generally adopt real-time calculation access, while composite data normally involve asynchronous access.

(2) All APIs are downgraded and fusible, and data traffic can be cut as needed.

(3) Since customer profiles are extremely confidential information, for security considerations, the inquiry service has a strict authority control scheme, and all information can only be accessed by authorisation.

(4) The company should be responsible for the accuracy of user information; for the purpose, there is a dedicated User Profile data visualisation platform verifying the consistency, availability, and correctness of the database.

\subsection{Alibaba and Buick China}

Alibaba has built and deployed an enormous industrial chain through self-built platforms and stocks investment and established multiple systems both online and offline, from shopping to social media (Alibaba, 2020). This allows Ali Group to obtain huge consumer data. Through their e-commerce platform, Alibaba captures detailed user purchasing data, including anonymous access, registration purchase data, order and delivery information; through the customer's frequency, product, and brand preference, their 
purchasing preferences can be recognised; in terms of games, Alibaba has established a mobile game platform that can identify users' game interests and engagement, and whether they will pay for the game to identify the user's leisure preferences; through Sina Weibo, the user's subscription and social relationship can be captured; financial products and services such as Alipay could effectively identify clients' real information, for instance consumer's legal name, age, income, deposit, etc.

Through the strategic arrangement of the above-mentioned industries and brands, Alibaba has collected various user data and carried out integrated analysis to establish a userrelated holographic marketing smart database and developed a DMP platform (data management platform). DMP is a visualised system to provide solutions for the problem of discovering target consumers for business in Alibaba's network. Companies can use this marketing tool to control key points in the entire marketing process, such as target setting, strategy selection, launch advertisement, target consumer filtrating, and marketing performance evaluation, and obtain data support from Alibaba's network. Figure 6 details the smart data and precision marketing process of DMP:

\section{Accessing data}

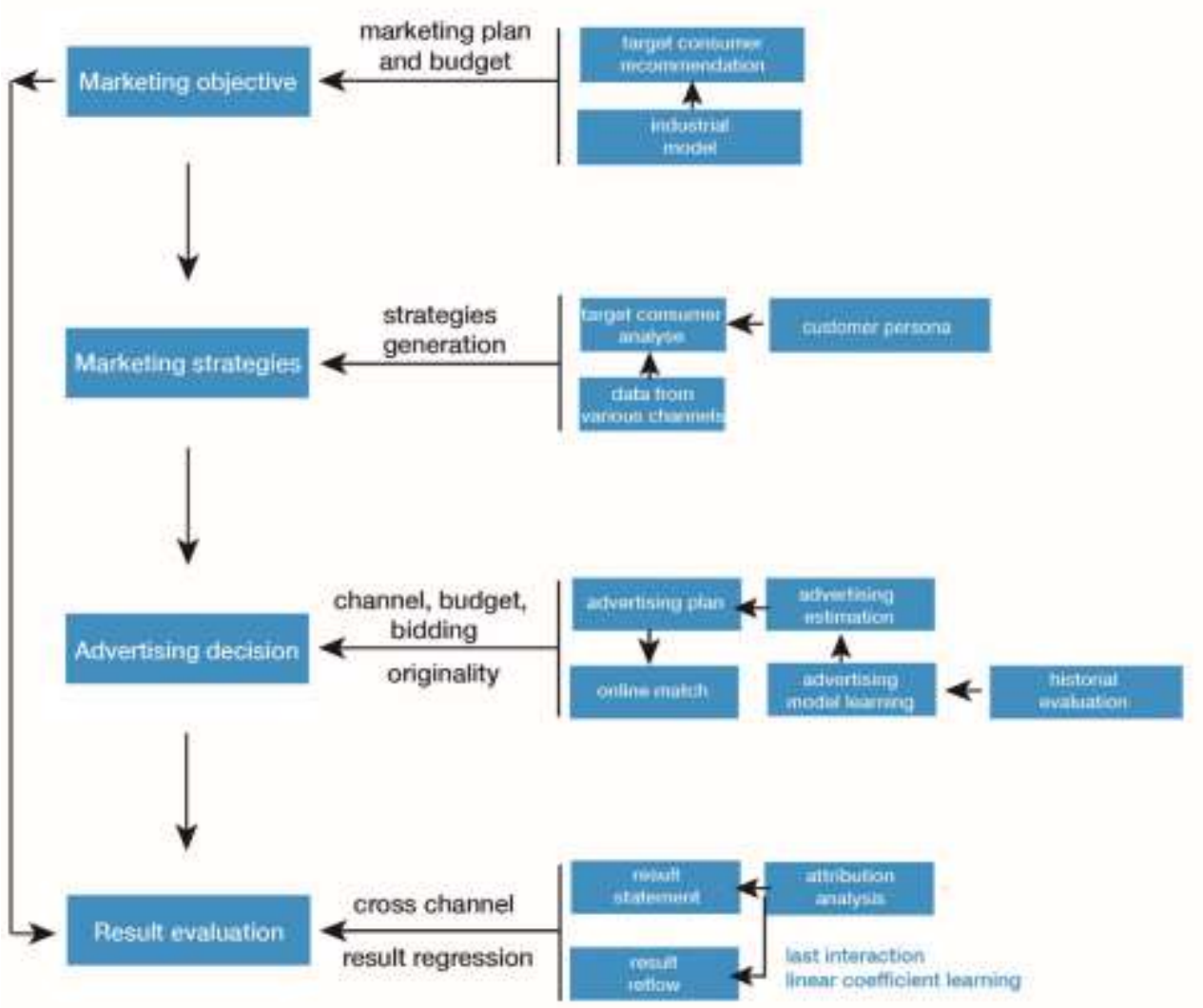

Omni-channels tracking

Figure 6. Workflow of DMP (Adapted from Wang, 2015)

Based on Alibaba's enormous smart database, Buick China and Alibaba initiated a precision marketing campaign in 2015, by analysing Alibaba's smart data to push advertisement accurately and increase consumer engagement (Wang, 2015). Buick launched a car whose slogan is "we know you". The marketing purpose is to deduce the characteristics of 
the new customer group according to the data of the browsing behaviour and purchase decisions of Alibaba's repeat consumers to identify and reach Buick's new consumers and increase the conversion rate and purchasing rate.

Buick carried out the data analysis of previous purchasers in the Alibaba back-end database to determine the tag attributes of the consumers. For instance, if consumers who are 25-35 years old, mainly female, have searched for Buick within 60 days, tag matching is performed and captured within Alibaba's database. Finally, the advertisement click and open rate increased to $136 \%$ compared to the estimation; $80.3 \%$ of customers who placed an order came from consumers selected by the smart database, which far exceeded Buick's marketing KPI (Wang, 2015).

Buick China's marketing is based on consumer behaviours and customer personas, and promotes different marketing information according to the preferences and characteristics of the different consumer groups to achieve personalised results, and thus to save budget and offer a perfect buying experience. The integration of "smart data" with "precision marketing" improves marketing efficiency.

\section{Discussion}

The Existing Problems and Possible Solutions of Smart Data and Precision Marketing 3.1 Isolated Data Island

As an enterprise develops into a certain stage, they will have plenty of business departments, where each department collects, analyses, and stores its own data independently. Therefore, each database will become an isolated island over time, and it is extremely difficult to connect and interact with other databases within the enterprise (Skogen, 2018). In simple terms, isolated data islands mean the databases do not have a correlation, and they are incompatible with each other.

In fact, this scenario exists in all large organisations across the globe. A survey from Dun \& Bradstreet of 510 U.S. and British companies illustrated that one out of nine companies suffered a penalty from the government due to data problems, and on average $20 \%$ of companies have lost customers due to their inability to integrate complete data. In the Asian context, currently, $92 \%$ of Chinese companies have internal isolated data islands, and $36 \%$ of them believe this is quite universal (PRNewswire, 2019). The negative aspect of isolated data islands is obvious. First, the management of databases is either repetitive or uncontrolled. Secondly, the work involving data analysis will be inefficient and a multi-module of the database cannot be shared and interacted with, which will lead to high cost and unsatisfactory effects of marketing communication.

To solve this problem, Google initiated a new technology of machine learning named federated learning, and it has another name in UC Berkley, Shared learning (Yang et al., 2019). The concept of this technology is to pool all the data into a hardware enclave and then learn the model without leaking the information. The following chart (Figure 7) showing the working process in an example from the health care industry. 


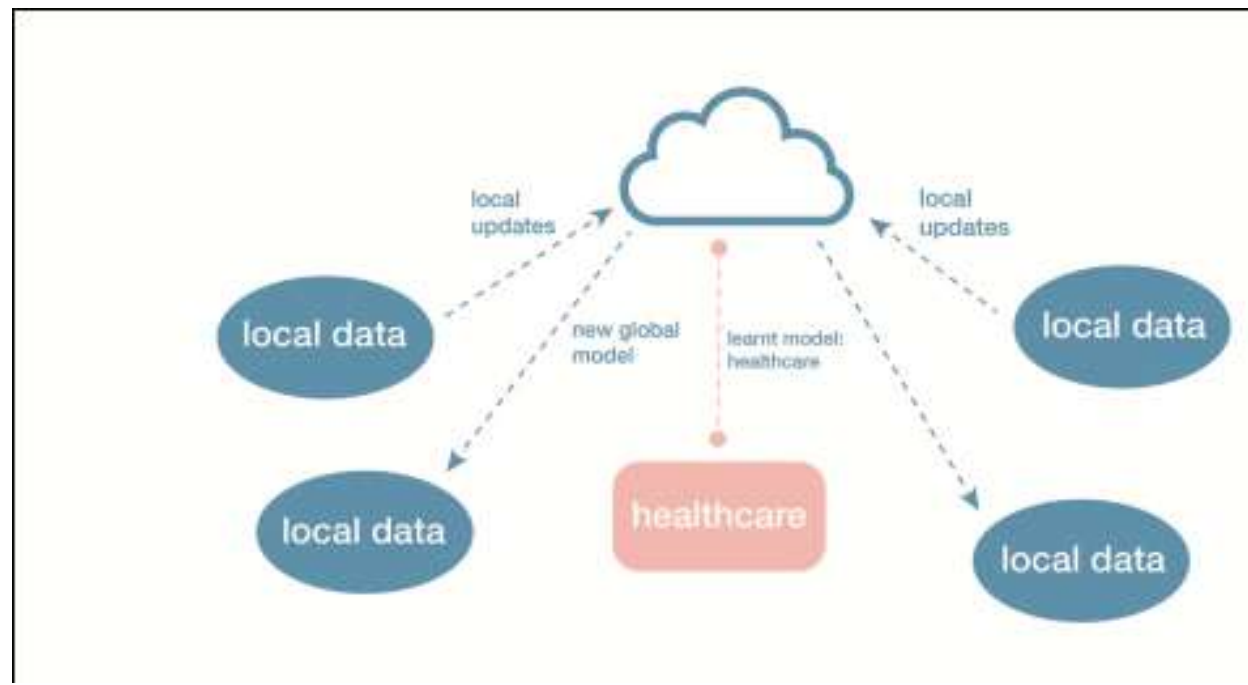

Figure 7. Federated Learning Model in Healthcare Industries (Adapted From Xu Et Al., 2020)

Although the new technology is taking shape, it is still in the nascent stage. From an organisation's perspective, they should make efforts to reduce the negative effects of the isolated data islands. Firstly, companies should build a team targeted on integrating databases across all departments, and transfer the data to business insights. Secondly, it is worthwhile establishing a unified standard of data assets. Brands should reach an agreement on how to define and collect data. This will greatly decrease the evaluation time and the complexity of the data chain. In addition, it is recommended that companies apply universal standards and APIs (application programming interface) to work with data. Through this method, the ways of sharing data will be more simple and easier, and data could be transferred and analysed smoothly and accessibly from one to another, so that efficiency will increase when communicating internally or with consumers.

\subsection{Sensitive Information Breach}

As we can see from the Shiseido and Trip cases, companies make every effort to collect and trace consumer behaviours to analyse them in order to build consumer persona, implement precision marketing, and provide better services and products. It is necessary to integrate all smart data before analysing; however, there is a risk of information being leaked and stolen. For instance, it was reported that Capital One suffered leakage over 100 million client profiles in 2019 (Flitter and Weise, 2019) due to the hacker attack, including sensitive information. The same issue arose in the Amazon S3 bucket in the same year, accidentally (Trend Micro, 2020). The Chinese video website Bilibili leaked massive confidential user data, including passcode and account information, due to leaks of the source code and loT logs (Sheng, 2019).

The basic measure of precaution against data leakage is to improve the legal and policy system. Since the smart data technology industry is still in its preliminary stage of development, there is no sound legal system to restrict and regulate the authorisation, management, and usage of the database. The transfer and collection of personal data needs to be strictly monitored and controlled.

Moreover, companies should not only improve their security technology constantly but also increase their awareness of information protection. Privacy issues require brands to take practical action to create solutions such as ameliorating authentication and authorisation, 
securing transactions, data encryption, etc.; customers' personal information should also be desensitised (Khalid et al., 2013). As in the Trip case mentioned above, where their system has an authority module, all inquiries must have permission to access.

Meanwhile, it is important for enterprises in different industries to jointly establish a comprehensive industry standard and act to protect data security and authorisation mechanisms.

\section{Conclusion}

\subsection{Contribution and Implication of Research}

This study remains a pilot study involving exploration of some Asian cases in the context of precision marketing. Smart data driven precision marketing has become a new trend involved in majority industries especially in retail industry. Combined with the theoretical basis and the features of smart data and precision marketing, this research provides a reference for businesses concerning the application of smart data and precision marketing. With smart data and precision marketing, companies could have a long-term sustainable development on discovering potential consumers and improving consumer retention rate, thus a new marketing mode can be established to help enterprises to achieve the goals of high marketing efficiency and revenues.

\subsection{Further Research Opportunities}

Further development of this research agenda is required, in a broader context. As smart data technology is an emerging technology, research on smart data and precision marketing is still in the exploratory stage. With the maturity of big data and AI technologies, smart data and precision marketing will inevitably have a profound impact on businesses in various industries.

\section{References}

Alam, J. R., Sajid, A., Talib, R., \& Niaz, M. (2014). A review of the role of big data in

Business, International Journal of Computer Science and Mobile Computing, 3, 446-453.

Alibaba group. (2020) Our business. Alibaba official site. Available at: https://www.alibabagroup.com/cn/about/businesses, [Accessed 10 January, 2021]

Eastmoney. (2020). Ttrip's 2019 financial report: Revenue exceeds the total of the last 5 years with the steady core business growth. Eastmoney. Available at: http://finance.eastmoney.com/a/202003191424149021.html, [Accessed 10 January, 2021]

Erevelles, S., Fukawa, N., \& Swayne, L. (2016). Big data consumer analytics and the transformation of marketing. Journal of Business Research, 69(2), 897-904.

Flitter, E., \& Weise, K. (2019). Capital One data breach compromises data of over 100 Million. The New York Times. Available at: https://www.nytimes.com/2019/07/29/business/capital-one-data-breachhacked.html, [Accessed 10 January, 2021]

Hamid, O., Smith, N., \& Barzanji, A. (2017). Automation, per se, is not job elimination: How artificial intelligence forwards cooperative human-machine coexistence. Paper presented at the IEEE 15th International Conference on Industrial Informatics (INDIN), 899-904. 
Khalid, U., Ghafoor, A., Irum, M., \& Shibli, M. (2013). Cloud based secure and privacy enhanced authentication \& authorization protocol, Procedia Computer Science, 22, 680-688.

Kotler, P., \& Armstrong, G. (2005). Principles of marketing. Pearson.

Liu, Y., Soroka, A., Han, L., Jian, J., \& Tang, M. (2020). Cloud-based big data analytics for customer insight-driven design innovation in SMEs. International Journal of Information Management, 51.

Marr, B. (2015) Why only one of the 5 Vs of big data really matters. IBM Big Data \& Analytics Hub. Available at: https://www.ibmbigdatahub.com/blog/why-only-one-5vs-big-data-really-matters, [Accessed 10 January, 2021]

Mayer-Schonberger, V., \& Cukie, K. (2013). Big data: A revolution that will transform how we live, work and think. John Murray.

Murgai, A. (2018). Transforming digital marketing with artificial intelligence. International Journal of Latest Technology in Engineering, Management \& Applied Science, 7(4), $259-262$.

Neslin, S., \& Shankar, V. (2009). Key issues in multichannel customer management: Current knowledge and future directions. Journal of Interactive Marketing, 23(1), 70-81.

Patrizio, A. (2018). Dobbs Journal. IDC: Expect 175 zettabytes of data worldwide by 2025, Network World, Available at: https://www.networkworld.com/article/3325397/idcexpect-175-zettabytes-of-data-worldwide-by-2025.html, [Accessed 10 January, 2021]

PRNewswire. (2019) 2019 Chinese Enterprise Digital Transformation and Data Application Research Report, PRNewswire, Available at: https://www.prnasia.com/story/258461 1.shtml, [Accessed 10 January, 2021]

Qin, X., \& Zhao, J. (2016). Research on big data application in precision marketing. Proceedings of the 6th International Conference on Electronic, Mechanical, Information and Management Society. Atlantis Press.

Qqcjw. (2018). Precision marketing is crucial for bank industry in the era of digital economy. Qqcjw. Available at: http://www.qqcjw.com/jj/20180928/19344.html, [Accessed 10 January, 2021]

$\mathrm{Qu}, \mathrm{J}$. (2020). Application of artificial intelligence and big data technology in digital marketing. Journal of Commercial Economics, 2020(10), 78-80.

Salazar, J. (2016) "Smart data is the future of Fintech" - Speaker Spotlight: Q\&A with Patrick Koeck - Data Natives Berlin 2016, Dataconomy. Available at: https://dataconomy.com/2016/09/smart-data-future-fintech-speaker-spotlight-qapatrick-koeck-data-natives-berlin-2016/, [Accessed 10 January, 2021]

Sheng, W. (2019). Bilibili source code containing user names and passwords leaked on GitHub. Technode. Available at: https://technode.com/2019/04/23/bilibili-sourcecode-leaked-on-github-containing-usernames-and-passwords/, [Accessed 10 January, 2021]

Shujike. (2019) How Ttrip build precisely customer personas among massive data, Shujike, Available at: https://www.shujike.com/zixun/20653.html, [Accessed 10 January, 2021]

Skogen, T. (2018). The curse of isolated data islands. Minerva. Available at: https://minervaplm.com/blog/posts-folder/2018/june/the-curse-of-isolated-data-islands/, [Accessed 10 January, 2021]

SocialBeta. (2017) Report: White paper on smart data, SocialBeta. Available at: https://socialbeta.com/t/report-socialbeta-smart-data-driven-marketing-2017-08, [Accessed 10 January, 2021]

Suh, B. (2015) Data blindness: Why we see data and don't act. Readwrite. Available at: https://readwrite.com/2015/09/21/data-blindness/, [Accessed 10 January, 2021] 
Treasure Data. (2020) How 3 Major Brands Transformed Their Customer Experience with a CDP, Treasure Data Blog, Available at: https://blog.treasuredata.com/blog/2020/12/07/infographic-how-3-major-brandstransformed-their-customer-experience-with-a-cdp/, [Accessed 10 January, 2021]

Treasure Data. (2020) The enterprise customer data platform. Treasure Data. Available at: https://www.treasuredata.com/product-overview-test/, [Accessed 10 January, 2021]

Trend Micro. (2020). Unsecured AWS S3 Bucket Found Leaking Data of Over 30K Canna bis Dispensary Customers. Trend Micro. Available at: https://www.trendmicro.com/vinfo/us/security/news/virtualization-andcloud/unsecured-aws-s3-bucket-found-leaking-data-of-over-30k-cannabisndispensary-customers, [Accessed 10 January, 2021]

Trip. (2020) About Ttrip, Trip official site, Available at: http://pages.ctrip.com/public/ctripab/abctrip.htm, [Accessed 10 January, 2021]

Wang, W. (2015). Research on The Online Precision Marketing of Haier Group Based on The user Big Data. Northeast Agricultural University.

Xu, J., Glicksberg, B.S., Su, C., Walker, P., Bian, J., \& Wang, F. (2020). Federated learning for healthcare informatics, Journal of Healthcare Informatics Research.

Yang, Q., Liu, Y., Cheng, Y., Kang, Y., Chen, T., \& Yu, H. (2019). Federated learning, Morgan \& Claypool.

Yu, C., Zhang, Z., Lin, C., \& Wu, Y. (2020). Can data-driven precision marketing promote user ad clicks? Evidence from advertising in WeChat moments,

Industrial Marketing Management, 90, 481-492.

Zabin, J., \& Brebach, G. (2004). Precision marketing: The new rules for attracting, retaining, and leveraging profitable customers. John Wiley \& Sons.

Zhao, S., \& Ma, J. (2017). Research on precision marketing data source system based on big data. International Journal of Advanced Media and Communication, 7(2). 